\title{
The Influence of Grain Boundary Precipitates on Creep Fracture
}

\author{
of Inconel 718
}

\author{
W.Chen and M.C.Chaturvedi \\ Dept.of Mechanical and Industries Engineering \\ The University of Manitobe \\ Winnipeg, Manitoba \\ Canada R3T 2N2
}

\begin{abstract}
The presence of $\delta$-precipitates at grain boundaries(GBs) in Inconel 718 , though generally believed to be detrimental to the fracture properties of the material, has also been reported to be beneficial in enhancing its ductility and toughness. The $\delta$ precipitates at GBs are normally produced by a modification of the heat treatment procedures. These modified treatments may also significantly alter the state of strengthening microstructure within the grain material at the same time. As a result, the actual effect of these $\delta$ particles at GBs on the mechanical properties of the alloy may be complex, and its analysis may not be as straight forward as has been assumed.

In this study, the Inconel 718 has been heat treated to obtain various materials with identical grain size and microstructures but with a different state of dispersion of $\delta$ precipitates at the GBs. The density of $\delta$ precipitates $(\rho)$ in different materials was from $0 \%$ to about $70 \%$. Creep tests have been conducted on these materials at $795 \mathrm{MPa}$ and $625^{\circ} \mathrm{C}$. It has been found that both the rupture time and total creep strain decrease with an increase in the value of $\rho$ when its value is below about $45 \%$. However, when the value of $\rho$ is above $45 \%$, both the rupture time and creep strain increase with an increase in $\rho$ to a value much higher than that observed in the material with zero $\delta$ precipitation at GBs. SEM observation of the crept samples and their fracture surfaces have shown that the presence of $\delta$ precipitates at GBs results in the formation of creep voids in all the specimens. However, the effect of creep voids on the final fracture of the material is dependent upon the value of $\rho$. At the lower value of $\rho$, creep voids are observed to be isolated, and the fracture may be due to the propagation of wedge crack initiated at triple points of grain boundaries. At a higher value of $\rho$, the probability of wedge crack formation may be reduced. The fracture will then be controlled by the rate of growth and propagation of creep voids at normal GBs, which is a much slower process than the formation of wedge cracks at triple points.
\end{abstract}

\footnotetext{
Superalloys $718,625,706$ and Various Derivatives Edited by E.A. Loria

The Minerals, Metals \& Materials Society, 1994
} 


\section{Introduction}

In the high temperature creep, the effect of precipitate particles at grain boundaries on the creep fracture is believed to not only depend upon the creep deformation conditions but also on the size of the particles $[1,2]$. When the size is either very small(less than $100 \mathrm{~nm})$, or very large ( $>50 \mathrm{um}$ ) strengthening through the precipitates can be achieved either by interaction with dislocations, or by load transfer. When the size is between the extremes, creep voids are normally associated with the precipitates instead of strengthening. As a result, it is generally believed that the presence of the precipitates is detrimental to the creep fracture properties of a material, since it is difficult for most engineering materials to have grain boundary precipitates with a size beyond the intermediate size range. This also holds true for Inconel 718 in which the $\delta$-phase, that is normally present at grain boundaries, has been often observed to be detrimental to its fracture properties [3].

To study the effect of precipitates at grain boundaries on the creep fracture behavior, many research projects have been conducted to obtain an understanding of the mechanism of precipitate-induced void formation, and their growth and propagation $[4]$. In contrast to this, little information is available on the effect of the density of grain boundary particles on the creep fracture behaviour. Such a study is important, because it is believed that the variation in the precipitate density at grain boundaries may be able to change the sliding conditions along the boundaries. This may, in turn, exert a beneficial influence on fracture behaviour. In this study, Inconel 718 has been heat treated to obtain various materials with identical grain size and microstructures but with a different state of dispersion of $\delta$ precipitates at the GBs. Creep tests have been conducted at $795 \mathrm{MPa}$ and $625^{\circ} \mathrm{C}$ on these materials in order to study the effect of the density of $\delta$-precipitates at grain boundaries on the creep fracture behaviour of Inconel 718.

\section{Experimental Methods}

The chemical composition of Inconel 718 used in this study, as determined by Arrow Lab, Wichita, Kansas(USA), is given in Table 1. A $2.54 \mathrm{~mm}$ thick sheet of the alloy was coldrolled to a thickness of $1.4 \mathrm{~mm}$ and machined into flat samples with a gauge dimension of 1.3 $\mathrm{mm} \times 5.3 \mathrm{~mm} \times 25.4 \mathrm{~mm}$. The creep samples were heat treated in accordance with the scheme illustrated in Table 2 , Which is based on the work of other investigators $[5,6]$, in order to obtain controlled and specific microstructures. The heat treated as well as creep deformed specimens were examined by a JEOL 840 Analytical Scanning Electron Microscope and a JEOL 2000FX Analytical TEM/STEM. The size and the number of precipitates at grain boundaries were analyzed based on the binary images created from the secondary electron image of the precipitates. Such analysis was carried out continuously on the entire grain boundaries of several grains. The total length of the grain boundaries being analyzed was also measured on the SEM micrographes. The average line density of precipitates at grain boundaries were calculated based on the number and the average size of precipitates on a given length of grain boundaries. More than a thousand particles on grain boundaries of at least 5 grains were scanned on each material. The creep tests were carried out at a temperature of $625^{\circ} \mathrm{C}$ and an applicd stress of $795 \mathrm{MPa}$ on Denison constant stress creep machines. The test temperature was controlled within $\pm 3^{\circ} \mathrm{C}$ and a flow of argon gas through the test chamber was maintained. Creep strain was recorded by a strip chart recorder.

Table 1. Chemical Composition of Inconel 718 (wt.\%)

$0.03 / \mathrm{C}, \quad 19.24 / \mathrm{Fe}, \quad 52.37 / \mathrm{Ni}, \quad 18.24 / \mathrm{Cr}, \quad 0.52 / \mathrm{Al}, \quad 0.97 / \mathrm{Ti}$, $3.07 / \mathrm{Mo}, \quad 4.98 /(\mathrm{Nb}+\mathrm{Ta}), \quad 0.007 / \mathrm{Mn}, \quad 0.007 / \mathrm{S}, \quad 0.30 / \mathrm{Si}, \quad 0.04 / \mathrm{Cu}$ 
Table 2 Heat treatment procedures for Inconel 718

\begin{tabular}{|c|c|c|}
\hline Material & Solution Treatment & Aging treatment \\
\hline $\begin{array}{l}\text { Clean } \\
\text { grain boundary }\end{array}$ & $1020^{\circ} \mathrm{C} \times 4$ hour (A.C.) & $725^{\circ} \mathrm{C} \times 25$ hour \\
\hline $\begin{array}{l}\delta \text {-phase on } \\
\text { grain boundary }\end{array}$ & $\begin{array}{l}1020^{\circ} \mathrm{C} \mathrm{X} 4 \text { hour (F.C.) } \\
+900 \sim 1000^{\circ} \mathrm{C} \text { for } 1 \text { hour }\end{array}$ & $725^{\circ} \mathrm{C} \times 25$ hour \\
\hline
\end{tabular}

\section{Microstructures}

\section{Results}

The microstructures of the specimens that were either air cooled or furnace cooled from solid solution treatment at $1020^{\circ} \mathrm{C}$ are presented in Fig. 1(a) and I(b) respectively. It is seen that in contrast to the air cooled material, which is free of any precipitates except for a few primary carbides, the furnace cooling has produced coarse precipitates of $\gamma^{\dagger}+\gamma^{\prime \prime}$ phases in the grain interior as well as small particles of $\delta$ phase at the grain boundaries. The furnace cooled material was given a partial solid solution treatment at a temperature in the range of $900^{\circ} \mathrm{C}$ to $1000^{\circ} \mathrm{C}$ to dissolve the intra-grain precipitates, but to preserve those present at grain boundaries. As shown in figure 2, the partial solution treatment at a temperature below $925^{\circ} \mathrm{C}$ was not successful in achieving this. However, when the temperature is $925^{\circ} \mathrm{C}$ or above, the specimens are free of all the intra-grain precipitates and the $\delta$-precipitates at grain boundaries have grown slightly as compared to those observed before the partial solid solution treatment.

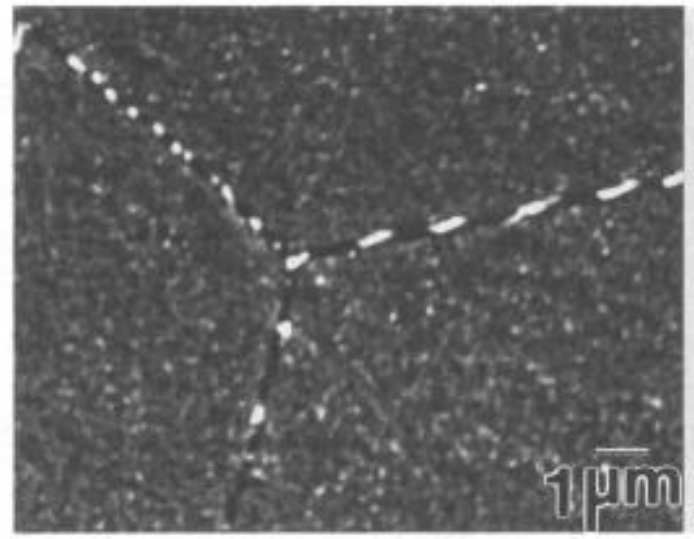

a)

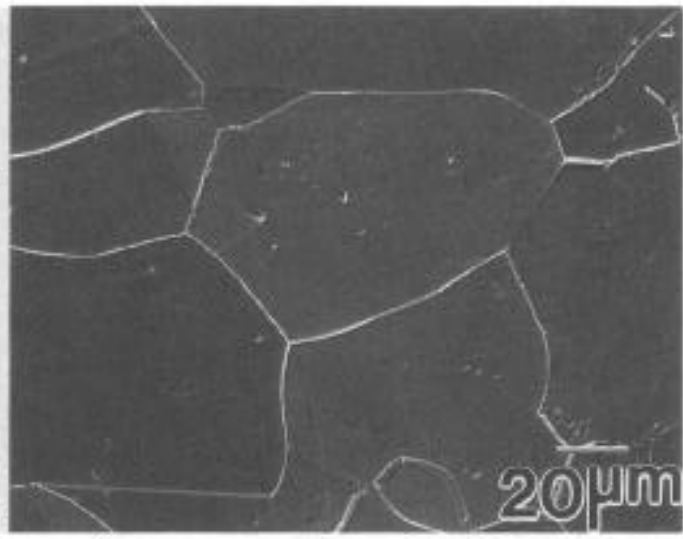

b)

Fig. I SEM photos showing microstructures of the material a) being furnace-cooled from solid solution treatment at $1020^{\circ} \mathrm{C}$ for 4 hours, b) being air-cooled from solid solution treatment at $1020^{\circ} \mathrm{C}$ for 4 hours

The precipitates at grain boundaries were quantitatively examined by SEM. The results are shown in Fig.3, where the average diameter, and the line density of the precipitates have been plotted against the partial solid solution treatment temperature. It is seen that, the average diameter of $\delta$ particles varies from $0.52 \mu \mathrm{m}$ at $925^{\circ} \mathrm{C}$ to $0.34 \mu \mathrm{m}$ at $975^{\circ} \mathrm{C}$ and the density from $67 \%$ at $925^{\circ} \mathrm{C}$ to $22 \%$ at $1000^{\circ} \mathrm{C}$. 


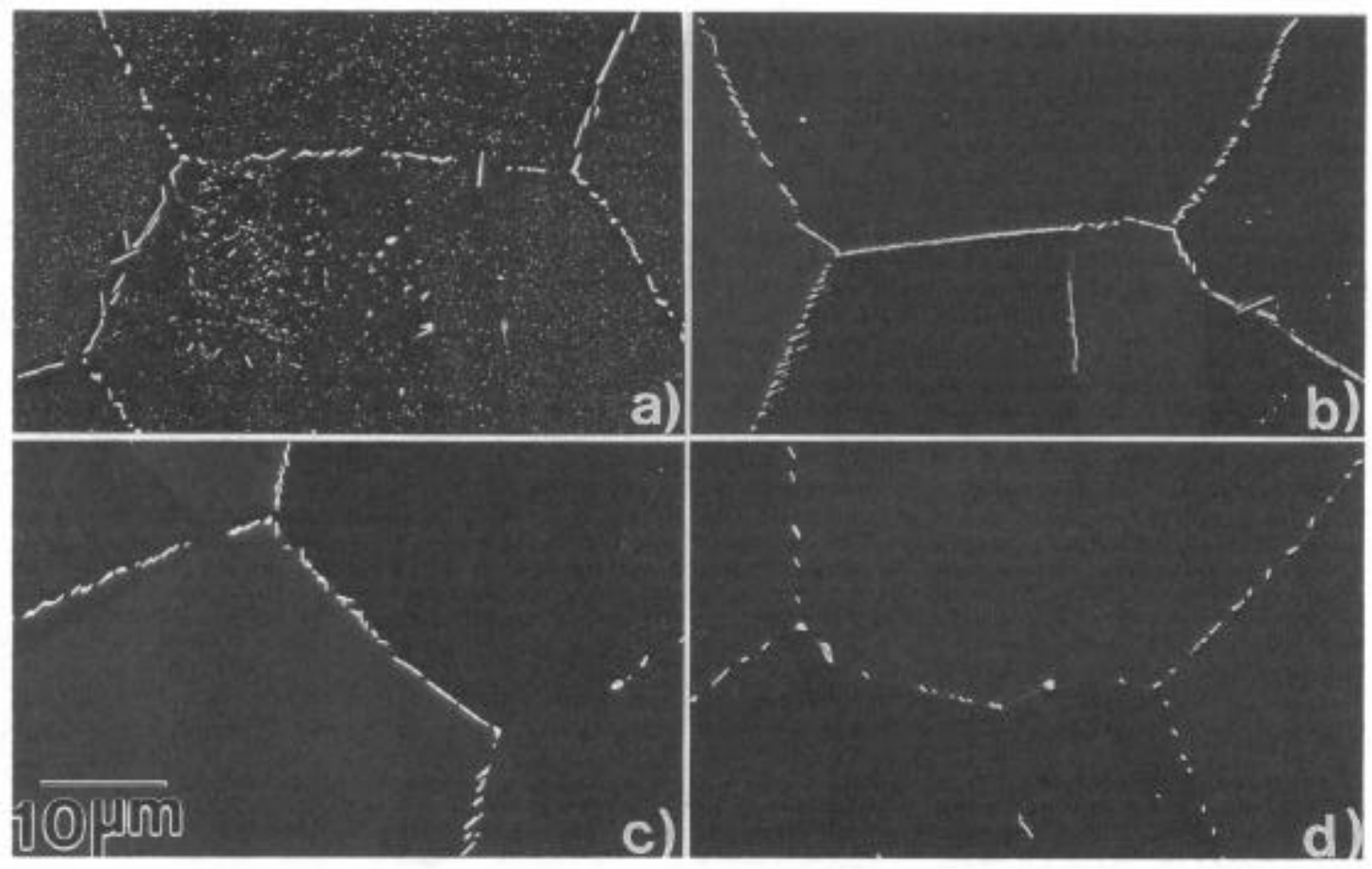

Fig.2 Microstructures of the materials being partially solid solution treated after furnacecooling. The partial solid solution temperature is a) $900^{\circ} \mathrm{C}$, b) $925^{\circ} \mathrm{C}$, c) $975^{\circ} \mathrm{C}$, d) $1000^{\circ} \mathrm{C}$.

Fig. 3 The effect of partial solid solution temperature on the parameters of $\delta$ precipitates at grain boundaries.

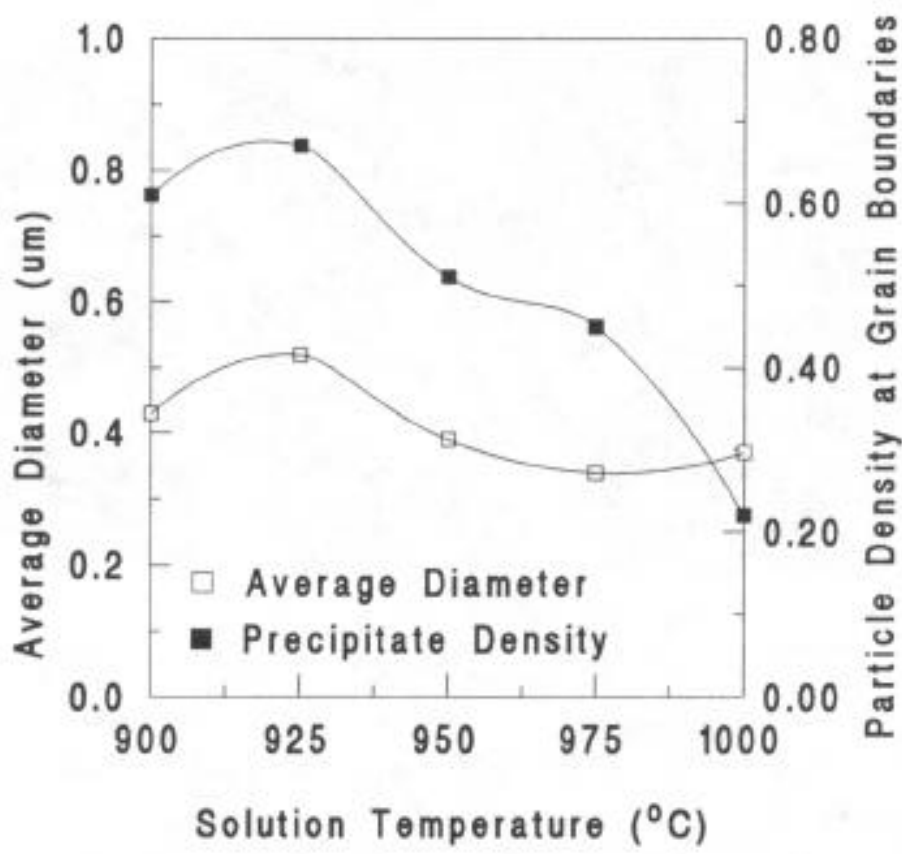

All the partial solution treated materials were aged at $725^{\circ} \mathrm{C}$ for 25 hours, which produced a homogenous distribution of $\gamma^{\prime}+\gamma^{\prime \prime}$ precipitates within the grains. It is seen in Fig. 4 that the size of $\gamma^{\prime}+\gamma^{\prime \prime}$ is the same in materials with clean grain boundaries as the material with $\delta$ precipitates at grain boundaries. The final grain size of all the specimens was found to be about $59 \mathrm{~mm}$. 


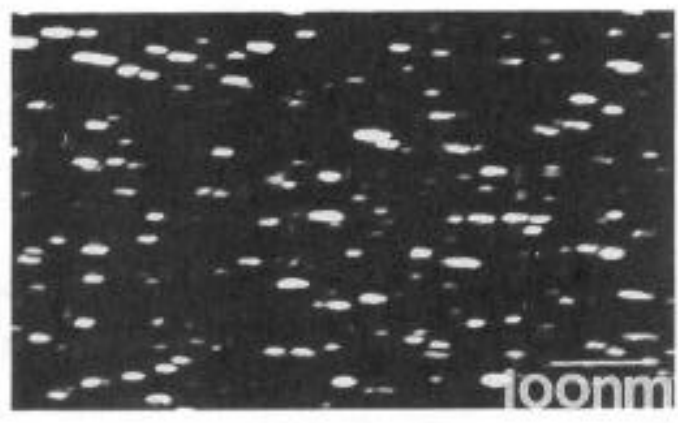

a)

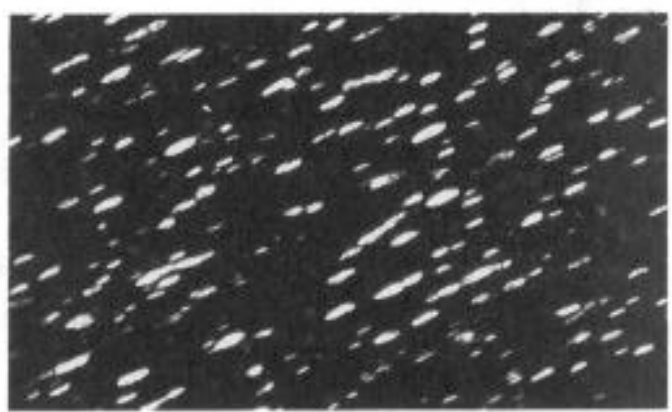

b)

Fig. 4 Similar size of $\gamma^{\prime \prime}+\gamma^{\prime}$ as precipitated in grain matrix from the aging at $725^{\circ} \mathrm{C}$ for 25 hours, has observed between the material with a partial solid solution treatment at $925^{\circ} \mathrm{C}$ (a) and the material with a clean grain boundaries (b).

\section{Creep tests}

Creep tests on specimens of various heat treated material were conducted at $795 \mathrm{MPa}$ and $625^{\circ} \mathrm{C}$. The creep curves of various specimens that were partially solution treated from $900^{\circ} \mathrm{C}-1020^{\circ} \mathrm{C}$ are given in Fig.5. The total rupture time and total creep strain are also plotted against the partial solution treatment temperature in Fig.6. It is seen that as the material is partially solution treated total creep strain initially decreases to a small extent. However, it increases very rapidly when the partial solution treatment temperature is reduced below $975^{\circ} \mathrm{C}$. The rupture time also decreases initially, but more rapidly, with an increase in the partial solution treatment temperature, however the minimum in its value is seen to occur at the same temperature of $975^{\circ} \mathrm{C}$.

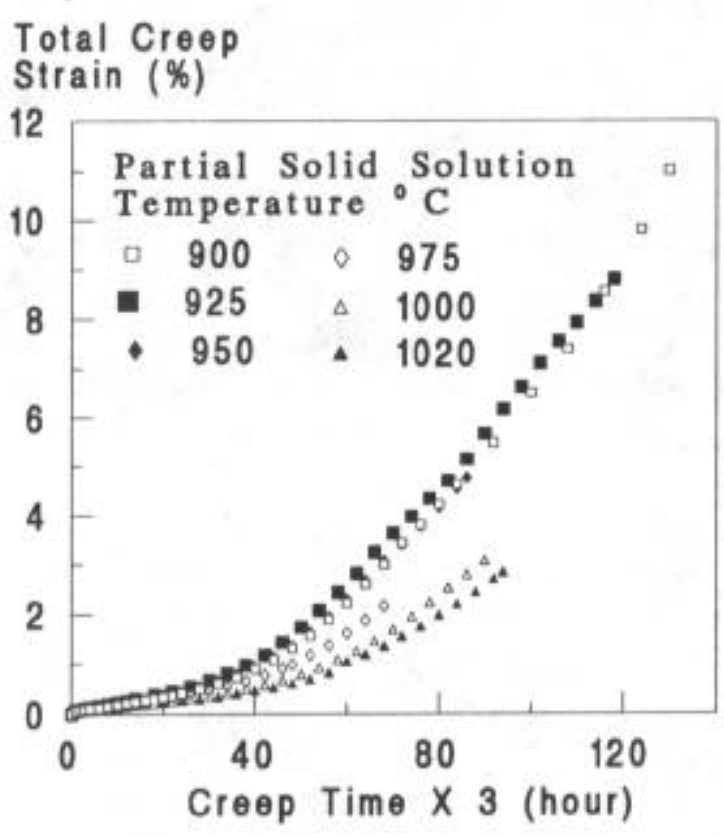

Fig.5 Creep curves obtained from the test at $625^{\circ} \mathrm{C}$ and $795 \mathrm{MPa}$ on the materials with a partial solid solution treatment at various temperatures.

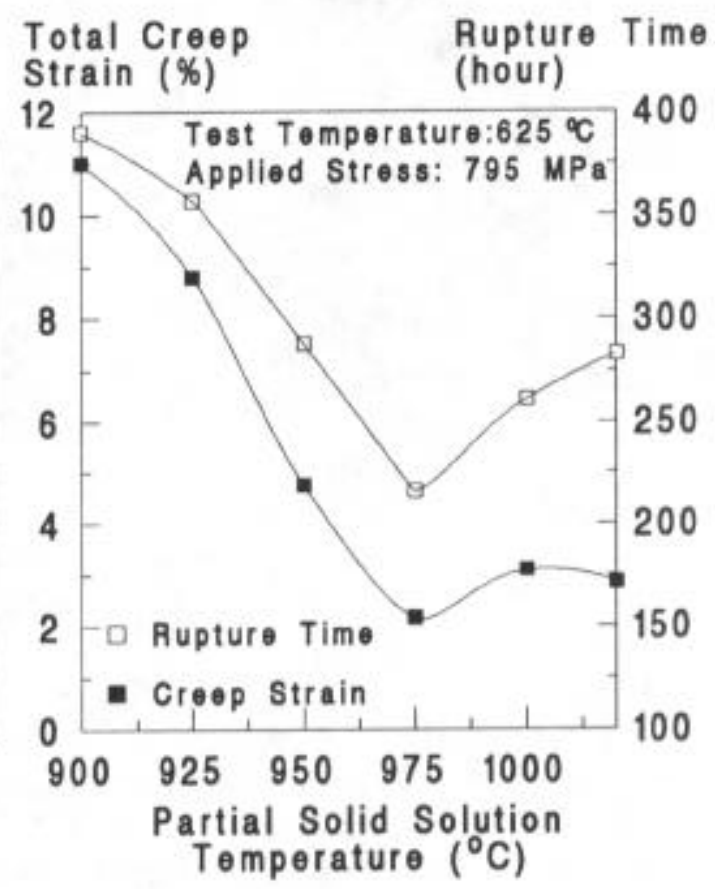

Fig. 6 Variation of total creep strain and rupture time with partial solid solution temperatures. 


\section{Fractographic Examination}

The fractographes of crept samples are shown in Fig. 7 and the observations can be summarized as follows:(1) The fracture is intergranular in all cases, whether precipitates are present at the grain boundaries or not. (2) For the material with clean grain boundries, occurrence of deformation on grain boundary's facets is not observed, though traces of slip lines in the grain interior are observed(Fig.7d). (3) When the solid solution treatment temperature is less than $975^{\circ} \mathrm{C}$, heavy deformation is observed at the interfaces of grains where many deformation dimples can be seen (Fig.9a and b). (4) Although massive precipitates are present at the grain boundaries in samples which were partially solid solution treated at and above $975^{\circ} \mathrm{C}$ temperature, however, no indication of grain boundary deformation is evident.

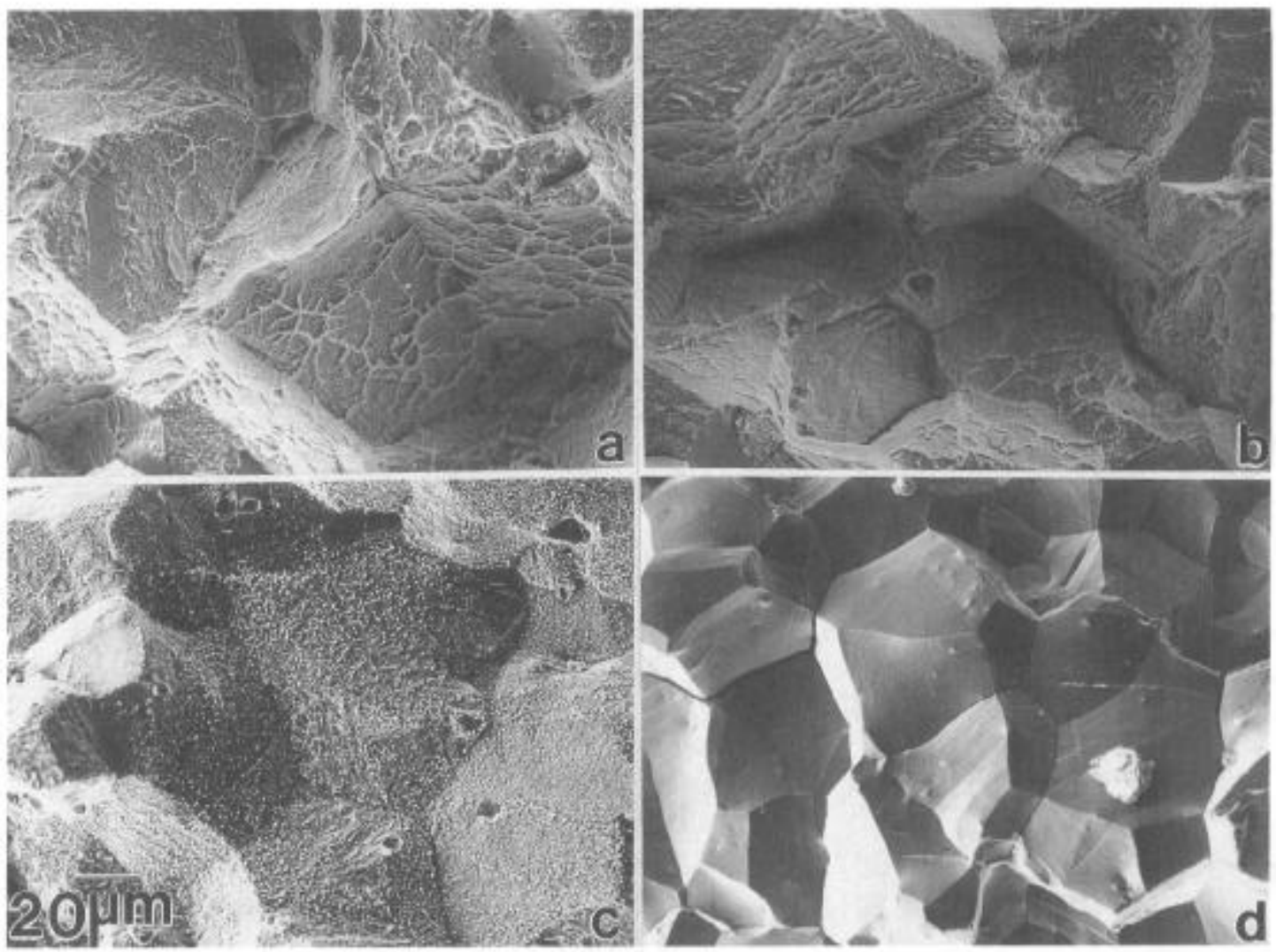

Fig. 7 SEM fractographes of the materials as being solid solution treated at a) $900{ }^{\circ} \mathrm{C}$, b) $925^{\circ} \mathrm{C}$, c) $975^{\circ} \mathrm{C}$, d) $1020^{\circ} \mathrm{C}$, and creep tested at $625^{\circ} \mathrm{C}$ and $795 \mathrm{MPa}$.

The polished flat surface of gauge section of failed samples was also examined by SEM to further study the creep fracture behaviour and typical micrographes are shown in figure 8 . It is seen that, (1) the wedge-like cracks at triple points of grain boundaries are dominant in the material with clean grain boundaries(Fig.8a). Some small creep voids on regular grain boundaries are also observed, though they are often associated with intersection site of slip lines and twins and grain boundaries; (2) the wedge cracks at triple points might initiate the fracture in the material with low density of precipitates at grain boundaries. The wedge cracks are seldom observed in materials with high density of precipitates at grain boundaries, instead creep cracks are often found on normal grain boundaries. 


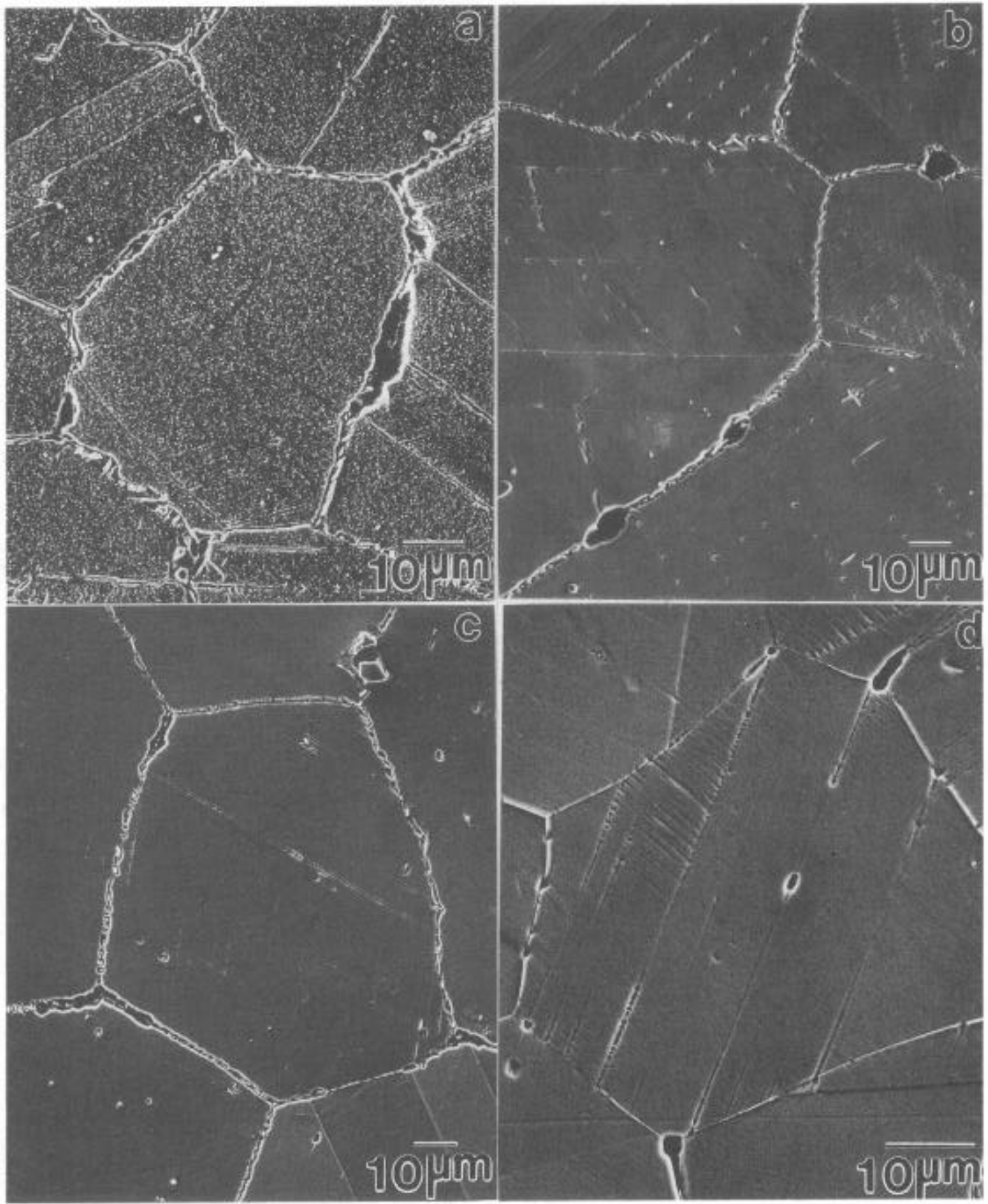

Fig. 8 Wedge cracks at the triple points of grain boundaries are often observed in the material with clean grain boundaries (a), and with a partial solid solution temperature at $975^{\circ} \mathrm{C}(\mathrm{b})$ and higher. Void-formed cracks are mainly found in the material with a solid solution temperature at $925^{\circ} \mathrm{C}$ (c) and $900^{\circ} \mathrm{C}(\mathrm{d})$., 


\section{Effect of Strength of Grain Materials}

\section{Discussion}

The formation of precipitates at grain boundaries will extract some $\gamma^{\prime}+\gamma^{\prime \prime}$-forming elements from the grain matrix, which may reduce the strength of the grain material. Since the softening of the grain material can assist the relaxation of stress concentration built-up around the precipitates, the initiation of creep voids might be delayed and they may require a longer time to link-up. This consideration might be especially significant for the material with a partial solid solution temperature of $900^{\circ} \mathrm{C}$, at which the coarse $\gamma^{\prime}+\gamma^{\prime \prime}$ particles, that pre-precipitated during furnace cooling, did not dissolve and had grown instead in the grain matrix. This is probably why the material has a much longer rupture time and can also undergo more deformation than the other materials that have either higher or less precipitate density at grain boundaries.

In considering the rupture behaviour of the material that was partially solution treated at or above $925^{\circ} \mathrm{C}$, the decrease in strength of the grain material, as discussed above, may not be a key factor in influencing the rupture time and total creep strain. This is because, as is observed in Figs. 5 and 6, the material with a solid solution temperature of $1000^{\circ} \mathrm{C}$ exhibits much higher values of rupture time and creep strain than the material treated at $975^{\circ} \mathrm{C}$, though the former should have a higher strength grain material since less precipitates have formed at the grain boundaries. That is, the grain boundary precipitates may be mostly responsible for the fracture behavior, while the weakening effect that occurred in grain matrix due to the formation of grain boundary precipitates might play only a minor role.

\section{Effect of Grain Boundary Precipitates}

It has been concluded by many researchers that precipitates at grain boundaries are only able to prevent the grain boundaries from sliding without introducing creep voids when they are either very large or very small[1]. In the present study, the size of precipitate at grain boundaries does not vary very significantly. In addition, the creep voids are observed in all cases. This suggests that precipitates at grain boundaries in Inconel 718 may play only a minor role in terms of their influence on creep resistance, and the variation in their size might be also not significant in controlling their fracture behavior. This suggestion can be evaluated by examining the dependence of rupture time and creep strain on particle size. This is shown in

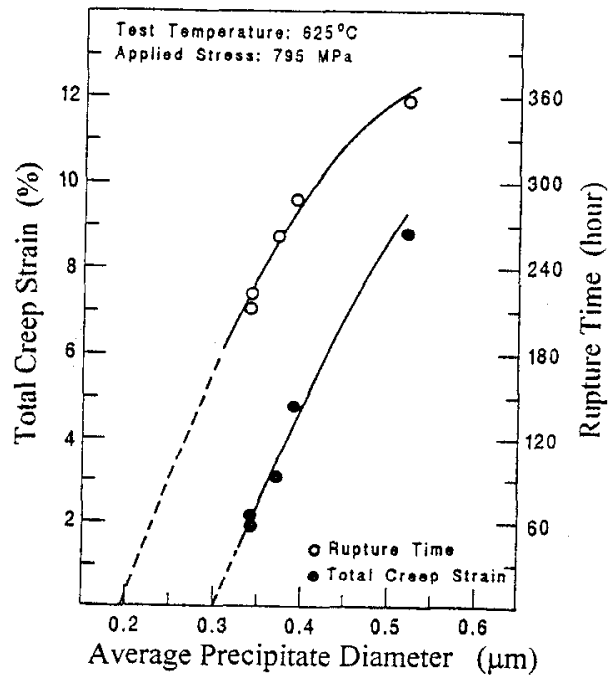

Fig. 9 Dependence of total creep strain and rupture time on the average diameter of precipitates at grain boundaries.

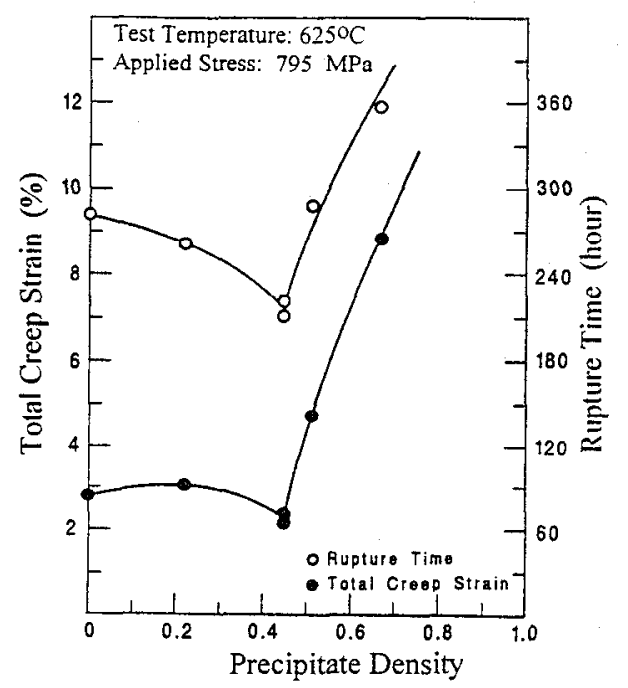

Fig. 10 Dependence of total creep strain and rupture time on precipitate density at grain boundaries. 
Fig.11 Skematical diagrams

illustrating the dependence of

creep time of creep strain on

particle density at grain

boundaries.

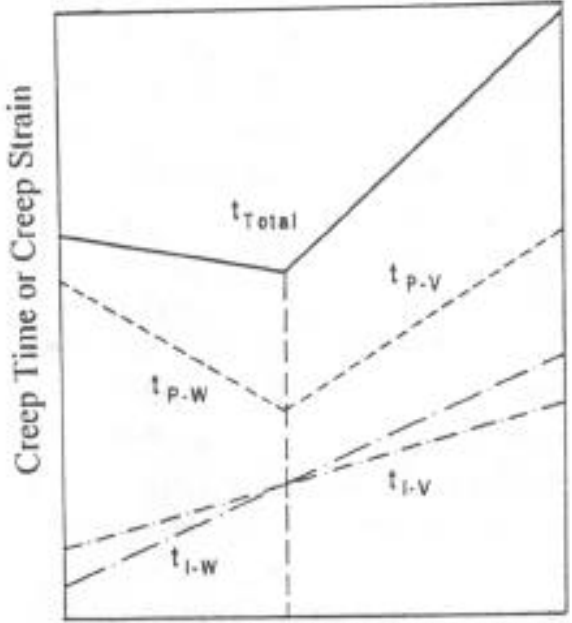

Particle Density at Grain Boundaries

cracks and the resistance to the propagation in the sliding direction of a grain boundary. It is believed that, an increase in precipitate density at grain boundaries, will decrease the shear stress available to act on the propagating cracks, and may also increase the resistance for propagation. Both these factors will decelerate the propagation process, as indicated by $t_{\mathrm{p}-\mathrm{V}}$ line in Fig. 11.

The above analysis of the manner in which the state of stress controls the crack propagation process, depending upon the nature of the crack can be verified by the examination of fracture surface shown in Fig. 7 and Fig.12. For example, the material with the lowest rupture time has been identified to fracture by the propagation of wedge crack. Its intergranular boundary facets are scattered with the precipitates and cavities with shapes similar to those of the precipitates that have been pulled out from the surface. Indications of deformation around the precipitates as well as on the boundary surface are not evident. This is also true for the material with a clean grain boundaries, in which the trace of slip lines due to the deformation of grain material are well preserved. In contrast to this, the material which is suggested to have fractured by the propagation of void-formed cracks shows massive deformation on the grain boundaries, which must be by a stress along the direction parallel to the boundary surfaces.

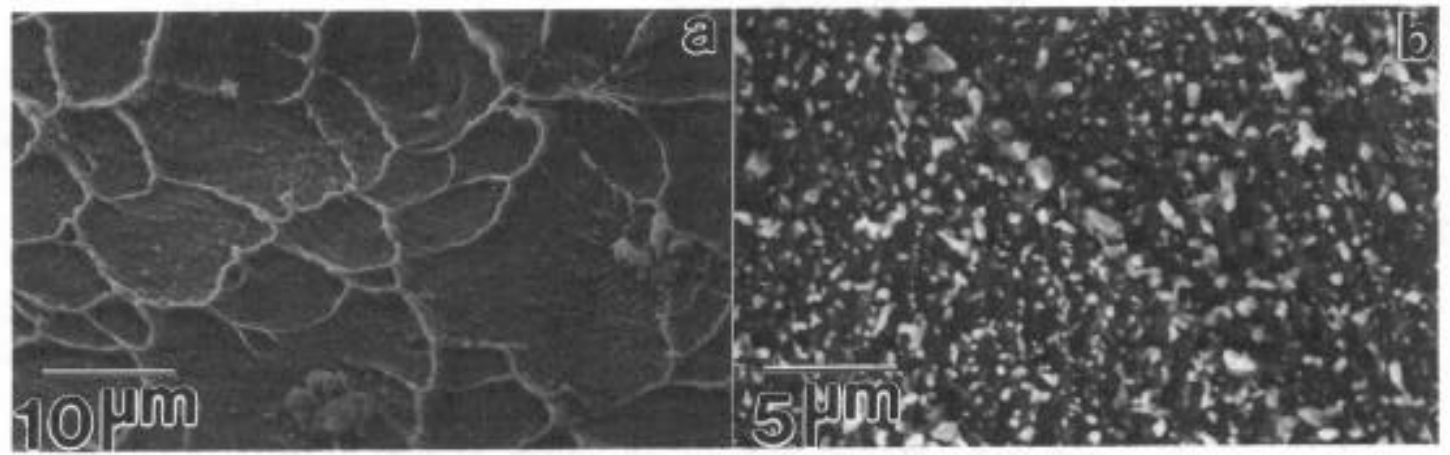

Fig. 12 SEM photos showing the microstructures on the intergranular surface of the material being partially solid solution treated at $900^{\circ} \mathrm{C}$ (a) and $1000^{\circ} \mathrm{C}$ (b) respectively.

The Complete Rupture Process The complete rupture process, as represented by a solid line in Fig 11, includes both the initiation and propagation process. In the low precipitate density region, an increase in the precipitate density at grain boundaries may increase the time needed for wedge cracks to develop, but will shorten the propagation process. For example, the 
Fig 9, in which both the rupture time and total creep strain are seen to increase with an increase in particle size. This is at variance with the variation in total creep strain and rupture time with the partial solution treatment temperature shown in Fig.6. In addition to the precipitate size, the partial solution treatment temperature also influences the inter particle spacing. Therefore, total creep strain and rupture time were also plotted and are given in Fig. 10. It can be seen that, a transition in the curve occurs when the particle density is about $45 \%$ which corresponds to a partial solid solution treatment temperature of $975^{\circ} \mathrm{C}$. This transition is also consistent with the microstructural and fractographic observations. Typical examples of fractographes and microstructures are shown in Fig. 7 and 8. It is seen that when the density of precipitates at grain boundaries is higher, then the rupture time and creep strain decrease with a decrease in precipitate density, and cracks that could lead to the final rupture are observed to develop at normal boundaries. However, when the density is lower, then the rupture time and total creep strain increase, although to a small extent, with a decrease in density of precipitates at grain boundaries. In this region fracture is characterized by the propagation of wedge cracks initiated at triple points of grain boundaries.

\section{Fracture Mechanisms}

Crack Initiation It is believed that in the high temperature creep, shear stress exists along grain boundaries. This shear stress may cause them to slide, which, in turn, may impose a concentration of stress at the triple points of the moving boundaries, leading to the formation of a wedge cracks [4].

When precipitates are present at grain boundaries, the sliding will be resisted by them, so that the possibility of developing a concentration of stress at triple points will be minimized. As a result, the risk of forming a wedge crack can be reduced. This implies that, an increase in the density of precipitates at grain boundaries will increase the incubation time for the initiation of a wedge crack at the triple points. This process is schematically illustrated by a straight line marked $t_{\mathrm{I}-\mathrm{W}}$ in Fig. 11.

When precipitates act as a barrier to grain boundary sliding, they can also act as stress concentrators. This stress concentration may be relaxed depending upon the size of the particles, or may cause the formation of creep voids, as it is observed in the present material. These creep voids may also grow and link up to a unstable crack size. With an increase in the precipitate density at grain boundaries, the time required for voids to become unstable cracks will also increase. This is because the higher the density, the value of the shear stress shared by each precipitate is reduced and a longer time is needed for the growth of such voids. This creep void-induced crack forming process is presented by a straight line denoted by $t_{\mathrm{I}-\mathrm{v}}$ in Fig. 11 .

The $t_{I-W}$ line intercepts the $t_{I-V}$ line. The intercept delineates the process of wedge-crack initiation at a triple point of grain boundaries and that of void-crack development on normal grain boundaries, i.e. wedge cracks are dominant in the material with lower density of precipitates at grain boundarics, whilc void-formed cracks might be associated in the material with higher density of precipitates at grain boundaries.

Crack Propagation After the crack has been initiated, its propagation will take place. The wedge cracks in the low density region will propagate in a way like a wedge chiseling into the openings. Therefore, the stress normal to the grain boundaries, and the bonding strength between the grains that may determine the propagation process. The presence of precipitates, which introduced creep voids around them, will actually weaken the bonding strength of the two grains in the direction perpendicular to the boundary. As a result, the propagation process can be accelerated with an increase in precipitate density at grain boundaries. This process is demonstrated by the $t_{\mathrm{P}-\mathrm{w}}$ line in Fig. 11.

In contrast to the propagation of a wedge crack, the propagation of void-formed cracks on a normal boundary may depend on the magnitude of the shear stress acting on individual 
material with clean grain boundaries or with a small amount of precipitates on them may require a shorter time to initiate a wedge cracks, but may need a longer time for them to propagate because of the smaller amount of damage caused by the smaller precipitates to the grain boundaries. This will reduce the total rupture time. When the grain boundary precipitate density is relatively high, the unstable cracks on a normal boundaries can develop earlier than wedge cracks at triple points, and the propagation process will rely on the shear condition along the grain boundary and increase the overall rupture time as the particle density is increased further.

\section{Conclusions}

1. When Inconel 718 is creep deformed at $795 \mathrm{MPa}$ and $625^{\circ} \mathrm{C}$ both the total creep strain and rupture time decrease with an increase of up to $45 \%$ in the density of precipitates at grain boundaries. Above this value of grain boundary precipitate density, total creep strain and rupture time increase with an increase in the density of grain boundary precipitates.

2. The SEM examination of the fracture surface has shown that wedge cracks form at the tripe points of grain boundaries when the material has a low precipitate density at grain boundaries. However, creep void-formed cracks on normal boundaries were often observed in the material that had high precipitate density at grain boundaries.

3. It has been suggested that, with an increase in the density of precipitates at grain boundaries the formation of wedge cracks at triple boundaries can be delayed to the stage where creep voids around precipitates at normal grain boundaries are able to grow into unstable cracks. The propagation of a wedge crack is driven by the stress normal to the boundary containing the wedge crack. Therefore, the propagation process will be accelerated by the presence of precipitates since they have reduced the grain boundary strength by the introduction of creep voids around them. However, the stress along the direction of grain boundary sliding might be the controlling force for the propagation of void-formed cracks as observed in the material with a higher density of precipitates at grain boundaries. As a result, the propagation process can be decelerated since an increase in the precipitate density at grain boundaries will decrease the magnitude of the shear stress that acts on the cracks and also increase the resistance to the crack propagation.

\section{Acknowledgments}

The authors would like to thank the Natural Science and Engineering Research Council of Canada for the financial support.

\section{Reference:}

[1]. A.S.Argon Recent Advances in Creep and Fracture of Engineering Materials and Structures ( Swansea, U.K.:Pineridge Press, 1982), 1-52

[2]. J.Rosler, A.G.Evans, "The Effect of Reinforcement size on the Creep Strength of Intermetallic Matrix Composites" Materials Science and Engineering 1992, no.A153:438-443.

[3] R.Muzyka and G.N.Maniar, "Effect of Solution Treating Temperature and Microstructure on the Properties of Hot-Rolled 718 Alloy" Metals Engineering Quarterly 1969, no.4: 23-37.

[4] J. Cadek, Creep in Metallic Materials, Materials Science Monographs,48 ( Amsterdam Elsevier, 1988) 271-343.

[5] A.K.Koul, P.Au,N.Bellinger, R.Thamburaj, W.Wallace and J-P Immarigeon, Developnment of A Damage Tolerant Microstructures for Inconel 718 Turline Disc Material, Superalloys 1988, The Metallurgical Society, 1988, 3-12.

[6] E Campo, C. Turco and V.Catena, The Correlation Between heat Treatment, structure and Mechanical Characteristics in Inconel 718, Metall. Sci. and Tech., J.Teksid (Italy), 1985, no:1, 16-21 